\title{
Factors Associated with Negative Attitudes towards Albinism and People with Albinism: A Case of Households Living with Persons with Albinism in Lake Zone, Tanzania
}

\author{
Methusela Mishael Masanja1, Marko Mwita Imori², Ismail Juma Kaudunde² \\ ${ }^{1}$ PO-Regional Administration and Local Government, Dodoma, Tanzania \\ ${ }^{2}$ Local Government Training Institute, Local Government Accounting and Finance Department, Dodoma, Tanzania \\ Email: methusela_masanja@yahoo.com,imori04@gmail.com, ismail.juma@yahoo.com
}

How to cite this paper: Masanja, M. M., Imori, M. W., \& Kaudunde, I. J. (2020). Factors Associated with Negative Attitudes towards Albinism and People with Albinism: A Case of Households Living with Persons with Albinism in Lake Zone, Tanzania. Open Journal of Social Sciences, 8, 523-537.

https://doi.org/10.4236/jss.2020.84038

Received: March 30, 2020

Accepted: April 25, 2020

Published: April 28, 2020

Copyright $\odot 2020$ by author(s) and Scientific Research Publishing Inc. This work is licensed under the Creative Commons Attribution International License (CC BY 4.0).

http://creativecommons.org/licenses/by/4.0/

\begin{abstract}
Assessment on factors associated with negative attitudes towards people with Albinism was conducted in northern part of Tanzania specifically in regions where higher incidences of albinos' killings were recently observed. A total of 156 respondents from households living with persons with albinism were involved in this study. Qualitative responses describing attitudes on albinism and people with albinism were transformed into numerical values (using a five points Likert Scales) to allow statistical computation. Measures of association and effect between several independent variables and the dependent variable were done using multiple linear regression analysis. Higher proportion of those interviewed (80\%) had negative attitudes towards albinism and people with albinism (PWA). In this study, education level determined attitudes of respondents whereby unfavorable attitudes were highly associated with education level and occupation of respondents $(p<0.001)$. Relationships between education, attitudes and awareness on albinism confirm the liberalizing effect of education on attitudes and general awareness. Widening the understanding on albinism will help on abandoning cultural beliefs related to albinism and its cause.
\end{abstract}

\section{Keywords}

Albinism, People with Albinism, Awareness, Education Level and Negative Attitude

\section{Introduction}

Attitudes that persons hold about albinism and persons with albinism (PWA) 
suggest their level of knowledge and understanding on the phenomenon (Ford, 2014). Attitudes on albinism can have tremendous impact on people with albinism though different people with albinism are affected differently depending on age, social standing and status (UNICEF, 2011). According to Mswela (2016), although albinism is common and affects several people in Africa, it still remains deeply misunderstood. From how people view albinism in Africa, babies born with albinism are vulnerable in multiple ways. Are vulnerable as children, as visually impaired, as socially ostracized, isolated and excluded, and as potential victims of witchcraft-related violence targeted for their body parts for use in "lucky" charms thought to bring good fortune (Taylor et al., 2019).

This study aimed at assessing attitudes towards albinism and people living with albinism and how different factors are associated with attitudes towards albinism and people with albinism among households' members in households living with persons with albinism. The study was conducted in regions most affected by attacks and killings of PWA in Tanzania. The research structure covers introduction of the study, methodology used to collect research data, results and discussions and lastly conclusions and recommendations.

\section{Methodology}

This study involved respondents from households living with persons with albinism in regions where attacks and killings of people with albinism were reported most. Four regions where most of the attacks and killings were reported were included in this study. Four districts (one district from each of the selected regions) were randomly selected. Households with persons with albinism were randomly selected from a list of households with persons with albinism in each of the selected district making a total of 156 respondents. A set of structured questionnaire was used for data collection from heads of households with PWA, people with albinism, and their relatives. The set of questionnaire was used to assess albinism awareness, attitudes towards albinism and PWA. The questions in the questionnaire included albinism awareness and attitudinal tests (for which a five points Likert scales was used).

To ensure validity, the study applied the triangulation technique by using interviews, focus group discussion in which the researcher was used checklist of questions so as to achieve data consistency and completeness and this was done through piloting of the data collection instruments used to collect data. Also in order to ensure reliability the researcher was selected the sample randomly with the help of the local people in the study area.

Data were edited, coded and analyzed using the Statistical Package for Social Sciences (SPSS) for Windows computer software. Descriptive statistics were computed including means, frequencies, percentages, cross-tabulations, and minimum and maximum values of various variables. Levels of albinism awareness among categories of respondents.

Qualitative responses descriptions of attitudes were transformed into numerical values (using a five points Likert scales) to allow statistical computation. 
Measures of association and effect between several independent (predictor) variables and the dependent variable were done using multiple linear regression analysis.

\section{Results}

\subsection{Albinism Awareness}

The levels of awareness on albinism among PWA, PWA's relatives and Heads of households were determined by administering awareness test to all 156 respondents who fell under different categories. Awareness scores categories were set, in which poorly aware was scores between 0 to 30 scores, while moderately aware was between 31 and 50 scores, aware was scores between 51 and 80 scores and highly aware was scores between 81 and 100 scores. The maximum score on the awareness test was 95 scores and the minimum score was 10 scores. The mean of the scores was 45.2 . Table 1 shows that, $50 \%$ of those who were poorly aware were Persons with Albinism and 50\% were relatives of PWA. Only 12\% of those who were highly aware were PWA. Several variables associated with levels of albinism awareness were tested. All the variables, except marital status and number of children with albinism were significantly associated with level of albinism awareness as seen in Table 2.

\subsubsection{Level of Albinism Awareness across Various Age Categories}

From the results in Table 2, there was significant association between categories of awareness in various age categories $(p=0.004)$. Among respondents aged below 16 years, $42.9 \%$ had poor knowledge and the rest (57.1\%) had moderate knowledge on albinism, while those with age above 60 years $(33.3 \%$ of them) were highly aware and none of them (0.0\%) performed poorly in albinism awareness test. Braathen (2005) in a study in Malawi, revealed that in general the community lacks proper information and knowledge about albinism. It was found that albinism was seen as a condition immersed in myths and superstition. According to Lund (2001), lack of knowledge about albinism leads to many superstitions which when combined with poverty magnifies problems related to skin and eyesight. This lack of correct knowledge on albinism, results in myths about albinos being spread which has horrifying effects on the albinos in Tanzania (Stensson, 2008).

According to Allen (2010), the ambiguity and general ignorance surrounding

Table 1. Awareness categories among categories of respondents with regard to albinism awareness.

\begin{tabular}{cccccc}
\hline $\begin{array}{c}\text { Poorly } \\
\text { aware }(\mathrm{n}=12)\end{array}$ & $\begin{array}{c}\text { Moderately } \\
\text { Aware }(\mathrm{n}=82)\end{array}$ & $\begin{array}{c}\text { Aware } \\
(\mathrm{n}=37)\end{array}$ & $\begin{array}{c}\text { Highly aware } \\
(\mathrm{n}=25)\end{array}$ & $\begin{array}{c}\text { Total } \\
(\mathrm{n}=156)\end{array}$ \\
\hline PWA & 50.0 & 23.2 & 21.6 & 12.0 & 23.1 \\
PWA's relatives & 50.0 & 45.1 & 59.5 & 60.0 & 51.3 \\
Heads of households & 0.0 & 31.7 & 18.9 & 28.0 & 25.6 \\
\hline
\end{tabular}


Table 2. Albinism awareness categories among respondents of different background.

\begin{tabular}{|c|c|c|c|c|c|c|c|}
\hline & \multicolumn{7}{|c|}{ Albinism awareness categories } \\
\hline & $\begin{array}{l}\text { Poor } \\
(\%)\end{array}$ & $\begin{array}{c}\text { Moderate } \\
(\%)\end{array}$ & $\begin{array}{c}\text { Aware } \\
(\%)\end{array}$ & $\begin{array}{c}\text { Highly } \\
(\%)\end{array}$ & $x^{2}$ & $P$-Value & $\begin{array}{c}\text { Significance } \\
\text { level }\end{array}$ \\
\hline \multicolumn{8}{|l|}{ Age categories } \\
\hline $0-15$ yrs $(\mathrm{n}=9)$ & 42.9 & 57.1 & 0.0 & 0.0 & & & \\
\hline $16-30 \operatorname{yrs}(n=26)$ & 11.5 & 46.2 & 26.9 & 15.4 & & & \\
\hline $31-45$ yrs $(n=64)$ & 1.6 & 60.9 & 28.1 & 9.4 & 28.923 & 0.004 & $* *$ \\
\hline $46-60$ yrs $(n=41)$ & 12.3 & 43.9 & 21.9 & 21.9 & & & \\
\hline $61-75$ yrs $(n=18)$ & 0.0 & 50 & 16.7 & 33.3 & & & \\
\hline \multicolumn{8}{|l|}{$\underline{\text { Respondents }}$} \\
\hline Albino $(\mathrm{n}=32)$ & 16.7 & 52.8 & 22.2 & 8.3 & & & \\
\hline PWA's relatives $(\mathrm{n}=32)$ & 7.5 & 46.3 & 27.5 & 18.8 & & & \\
\hline Heads of family $(\mathrm{n}=32)$ & 0.0 & 65.0 & 17.5 & 17.5 & 11.556 & 0.073 & ns \\
\hline \multicolumn{8}{|l|}{$\underline{\text { Sex }}$} \\
\hline Males $(\mathrm{n}=92)$ & 5.4 & 44.6 & 30.4 & 19.9 & & & \\
\hline Female $(n=64)$ & 10.9 & 64.1 & 14.1 & 10.9 & 10.234 & 0.017 & * \\
\hline \multicolumn{8}{|l|}{ Occupation } \\
\hline Peasants $(n=130)$ & 7.7 & 56.9 & 26.9 & 8.5 & & & \\
\hline Government employees $(\mathrm{n}=19)$ & 0.0 & 26.3 & 10.5 & 63.2 & 54.214 & $<0.001$ & $* * *$ \\
\hline Traditional. leader $(\mathrm{n}=4)$ & 50.0 & 50.0 & 0.0 & 0.0 & & & \\
\hline Religious leader $(\mathrm{n}=3)$ & 0.0 & 33.3 & 0.0 & 66.7 & & & \\
\hline \multicolumn{8}{|l|}{ Education level } \\
\hline Non formal $(n=23)$ & 34.8 & 56.5 & 8.7 & 0.0 & & & \\
\hline Primary $(\mathrm{n}=115)$ & 3.5 & 60.0 & 30.4 & 6.1 & $1.353 \mathrm{E} 2$ & $<0.001$ & $* * *$ \\
\hline Secondary $(\mathrm{n}=16)$ & 0.0 & 0.0 & 0.0 & 100.0 & & & \\
\hline Beyond secondary school $(\mathrm{n}=2)$ & 0.0 & 0.0 & 0.0 & 100.0 & & & \\
\hline \multicolumn{8}{|l|}{ Religion affiliation } \\
\hline Christian $(\mathrm{n}=125)$ & 4.8 & 48.8 & 26.4 & 20.0 & & & \\
\hline Muslim (n = 8) & 0.0 & 100 & 0.0 & 0.0 & 20.787 & $<0.001$ & $* * *$ \\
\hline Traditionists $(\mathrm{n}=23)$ & 26.1 & 56.5 & 17.4 & 0.0 & & & \\
\hline \multicolumn{8}{|l|}{$\underline{\text { Marital status }}$} \\
\hline Not married $(n=44)$ & 11.4 & 50.0 & 18.2 & 20.5 & & & \\
\hline Married $(\mathrm{n}=99)$ & 4.0 & 54.5 & 25.3 & 16.2 & 10.406 & 0.319 & ns \\
\hline Divorced $(\mathrm{n}=4)$ & 25.0 & 50.0 & 25.0 & 0.0 & & & \\
\hline Separated $(n=9)$ & 22.2 & 44.4 & 33.3 & 0.0 & & & \\
\hline \multicolumn{8}{|l|}{ Ethnic group } \\
\hline Sukuma $(\mathrm{n}=150)$ & 8.0 & 54.0 & 21.3 & 16.7 & & & \\
\hline Nyamwezi $(\mathrm{n}=2)$ & 0.0 & 50.0 & 50.0 & 0.0 & 14.400 & 0.025 & * \\
\hline Other $(n=4)$ & 0.0 & 0.0 & 100.0 & 0.0 & & & \\
\hline
\end{tabular}

${ }^{*}=$ significant at $p \leq 0.05 ;{ }^{* *}=$ significant at $p \leq 0.01 ;{ }^{* *}=$ significant at $p \leq 0.001 ; \mathrm{ns}=$ not significant. 
the condition of albinism, causes gross violations of human rights from both the public and private sphere which, as a result, prevent access to resources and perpetuate a state of neglect and abuse among persons with albinism. According to Lund (2005) as quoted by Moe (2011), it is obvious then that, due to lack of awareness of albinism in general society then it means that teachers and classmates are likely unaware of problems with eyesight and as a result maintain the belief that people with albinism have lower-than-average intelligence. Nzagi (2009) insists that lack of awareness of the condition is not only among those in rural areas, but also trained medical professionals. Thus, PWA's quality of life is severely affected and worsened by the lack of community awareness (Kiprono et al., 2012).

\subsubsection{Level of Albinism Awareness among Respondents of Various Status}

The results in Table 2 show that there was strong association between albinism awareness and social status of respondents $(p<0.001)$. Since some household members (PWA's relatives) were also community leaders, they had been purposely capacitated by being given the correct information about albinism as a means of dealing with the problem at community level, and it is obvious that community leaders had either primary school education or secondary education. Community leaders were involved in intervention to save PWA's lives through community engagement not only in Tanzania but also in other African counties (PHPAFRICA, 2012). UNICEF lauded such measures and it is called on the judiciary, the media, religious leaders, politicians and communities to bolster the response and weed out deeply-rooted superstitious beliefs that incite the murders (UN, 2008). It was critically important to engage communities through community leaders in which albinos lived if stigmatization and discrimination that negatively affect PWA's lives were to be mitigated. This is because murders of PWA are, to a large extent, fuelled by spiritual, cultural and or religious beliefs as well as lack of understanding of the causes of albinism (PHPAFRICA, 2012).

\subsubsection{Level of Albinism Awareness among Males and Females}

Level of awareness was significantly associated with sex of respondents in which males were slightly more aware of albinism than females $(p=0.017)$. Relatively poor awareness among females can be explained in the light of gender inequality in African cultural family settings in which women have unequal access to information compared to men (McLin-Bronson et al., 2009). Traditions which ignore women's wellbeing are deeply rooted in African communities which place women at a disadvantage in many aspects. Like in many African traditions, women in rural Sukumaland where traditions still dominate are required to remain silent and besides being unable to demand their rights they rarely have the chance to speak freely and express themselves. While insufficient information and communication network being an obstacle to improving women status, men's attitudes are unsupportive of women's efforts (Rwebangira, 1996). 


\subsubsection{Level of Albinism Awareness and Respondents' Occupation}

Respondents who were government employees and religious leaders were more aware than peasants and traditional leaders $(p=0.001)$. This reflects how they are deeply rooted traditions in the study area among peasants and traditional leaders who are mainly indigenous in the study area. Ignorance, prejudice, traditional beliefs and poverty are what drive people to kill albinos under the influence of witchdoctors and the belief in traditional magic which are still strong in many remote villages (Hogan, 2012). The killings indicate that there are some primitive, superstitious beliefs attached to people in the study area that make some wicked men to continue hunting PWA (Good \& Bad Culture, 2012). In general people in this area don't look at the PWA as part of the community but still stand firmly in their traditional beliefs (Aljazeera, 2009).

\subsubsection{Level of Albinism Awareness and Respondents' Education Levels}

Albinism awareness was highest among those with secondary school education (100\%) and those with education beyond secondary school (100\%). Two thirds $(60 \%)$ of those with primary education and those with no formal education (56.6\%) had moderate awareness. The association between awareness among groups and different education level was significant $(p<0.001)$. As a result, many rural areas where most of the killings have been taking place were poor and not able to afford to fulfill their basic things like accessing high and quality education. In these areas, primary level of education was the highest level the majority had reached. Since education plays major role in one's life like creating awareness and knowledge, which helps one to make critical decisions in life, then because of lack of education people become ignorant and involve themselves in inhumane acts (Mtholyoke, 2009). It is obvious then that Tanzania and the international community as a whole need to make serious commitments to raise awareness about albinism.

Tanzanians in rural areas where the killings have been taking place mostly need to be educated so that discrimination against and the murder of PWA can stop. Lund (2001) suggests further that, since an understanding of the pattern of inheritance where affected babies are born to two carrier parents would help to counter stories of albinism being a curse placed on a family or evidence of the mother's infidelity then genetic education is sorely needed to improve social integration of this group. Furthermore, Lubus (2010) insists that it is important to educate the entire society which is illiterate and unaware that albinism is a genetic defect that causes a lack of pigmentation in skin, eyes and hair and not the ghost sent to kill community or family members or that PWA contain magic power which can make someone rich.

\subsubsection{Level of Albinism Awareness and Respondents' Religious Affiliation}

About a half of Christians (48.8\%), all Muslims (100\%) and more than a half of traditional believers (56.5\%) were moderately aware of albinism. However, $26.1 \%$ of traditional believers were poorly informed, and $20 \%$ of Christians were 
highly aware of albinism. Statistically, the association between albinism awareness and religion affiliation was significant $(p<0.001)$. Traditional believers in the study area agreed that use of human body parts in preparations of charms is commonly practised in the area. Albino parts are believed to be the best parts especially the males and females private parts (Lubus, 2010). According to UTSS (2012), the Sukuma (the dominant ethnic group in the study area) traditionally killed their babies with albinism as soon as they were born and baby's remains were used for witchcraft rituals. Therefore, poor awareness among those who believe in traditions reflects what dominates in their mind.

According to Tanner (2010), due to beliefs rooted in traditions, PWA used to be killed by groups of Sukuma so that parts of their bodies could be used in the preparation of supposedly protective magic medicines. The medicines could be used to relieve a range of suspected and real misfortunes, ranging from witchcraft to the prevention of rain and the spread of AIDS as well as to increase the possibilities of success. Being largely religious but still adhering to traditions, people are still very rooted in superstitions, that is why Dave-Odigie (2010) observed that public enlightenment strategies to deal with the issue and sensitizing the populace should be strengthened but there is no denying the fact that it will take more than awareness and education to stop superstitions discrimination and stigma against PWA in this area.

\subsubsection{Level of Albinism Awareness and Respondents' Ethnic Groups}

Table 2 show that there was significant association between respondents of different ethnic groups and albinism $(p=0.025)$. The Sukuma ethnic group was less aware compared to other ethnic groups in the study area. More than a half (54\%) of Sukuma people were moderately aware, being slightly lower than Nyamwezi (50\%) who were also moderately aware. Eight percent $(8.0 \%)$ of the respondents from the Sukuma ethnic group were poorly aware while other ethnic groups had no respondents who were under this category. All (100\%) other ethnic groups (i.e. neither Sukuma nor Nyamwezi) were aware compared to Nyamwezi (50\%) and other ethnic groups (18.2\%). About one-fifth (20.5\%) of the respondents from the Sukuma ethnic group were highly aware while none were highly aware from the respondents from other ethnic groups. The association between awareness and different ethnic groups was statistically significant $(p=0.025)$. This reflects cultural beliefs which may have been an obstacle to the clear understanding of albinism. According to Tanner (2010) the Sukuma ethnic group members were most reported being responsible for the persecution of PWA. Their witchdoctors teach that PWA's body parts, skin, hair and blood, when combined with other ingredients and rituals performed by the witchdoctors and made into potions bring power and wealth to people. One of prominent Tanzanian newspapers, The Guardians on Sunday (IPPMEDIA, 2012) reported as follows:

"Dozens of Albinos are killed mainly in Sukumaland, in north-west Tanzania because of the belief that parts of their bodies could be used in the preparation of 
supposedly protective 'magic' medicines which could be used to relieve a range of suspected and real misfortunes, ranging from witchcraft to the prevention of rain and the spread of AIDS as well as increasing the possibilities of success ..."

The killings are said to be due to witchdoctors in this area who require PWA's body parts which are believed to provide the potent ingredient for magic charms, which many local people use believing to prosper (BBC, 2008). The beliefs, being held by the majority in the study area, affect clear understanding of the scientific facts of albinism.

\subsection{Assessment of Attitudes towards Albinism and PWA}

In determining level of attitudes among interviewee, a five points Likert scale including strongly disagree, disagree, undecided, agree and strongly agree was used to measure attitudes towards albinism and PWA.

\subsubsection{Respondents' Attitudes towards Albinism and PWA}

The five point scales were summarized to make three scales. Half of the statements in the Likert scale had negative connotations while the other half had positive connotation. The most negative attitude was represented by 20 , the neutral attitude was represented by 60 and the most positive attitude was represented by 100. The range of points for negative attitude was 20 to 59; and that of points for positive attitude was 61 to 100 .

The results showed that, over four-fifth $(80 \%)$ of respondent had negative attitudes towards albinism and PWA, 9\% had positive attitudes and $11 \%$ were undecided. Like in other communities across the world, albinism is hardly understood in this area too. Due to negative attitudes towards albinism and PWA, many women have been divorced by their husbands and shunned by families after giving birth to children with albinism (Kiprono et al., 2012). They have been accused of sleeping with men of other races, of being cursed and unclean, and of being witches thus abandoned by spouses and isolated in their communities (Wilkinson, 1998). Children with albinism have also been hidden from the public, forbidden from socializing with others and treated as outcasts (Thuku, 2011).

During data collection, it was obviously observed that, due to negative attitudes towards PWA, they seemed not to trust anybody (including neighbors and community leaders), not confident and felt inferior beings. One respondent (a person with albinism) dared to tell us that:

"I don't believe that I could sit and talk to any educated people. We are normally mistreated by our brothers and sisters who see us as useless and inferior beings ..."

Due to negative attitudes towards PWA, derogatory names for persons with albinism were commonly used in the study area. It is obvious that such names lead to prejudice and stereotypes which lead communities to condemn PWA basing on their condition rather than appreciating their humanity. Due to negative attitudes, PWA suffers rejection by the community, denial of the right to found families and killings done for a purpose of getting their body parts. These 
pose serious impacts on their psychological and economic status. Negative attitudes in these regions may be due to what historically happened in the past among the Sukuma in response to albinism. Children with albinism were instantly killed at birth for fear of shame attached to the condition or beliefs that they carry bad luck, in some cases birth of a child with albinism resulted into marital discord, leaving children without proper parental care (Rohwerder, 2018; UN, 2016).

Due to such attitudes towards albinism, then it seems that in the study regions, murders went on unreported for a long time and thus there is no reason to believe that it has ended (Jozen, 2012). Since the killings are due to witchcraft beliefs which has been a potent force in African life for a long time and goes far back into prehistoric times it thus continues today, not only among primitive people, but also among the civilized (Nemec, 1974). It is then obvious that it is difficult to detach Africans still committed to their traditional religions from cultures that existed before the coming of Christianity and Islam (The Citizen, 2011).

Five variables were tested using chi-square statistical test to determine their association with attitudes towards albinism and PWA. The results are summarized in Table 3. Education and type of work showed significant association with attitudes towards Albinism and PWA. However, attitude had no significant association with age, type of respondent, religion and sex. The result confirms the relationship between education and attitudes in which there is liberalizing effect of education on attitudes (Ohlander et al., 2005). This shows that, education can help in changing people's attitudes.

\subsubsection{Association between Respondents' Education Level and Attitudes towards Albinism}

From the results in Table 3, all who had not gone to school and $88.7 \%$ of those with primary school education had negative attitudes towards albinism and PWA. More than two-thirds (68.8\%) of those with secondary education and 50\% of those with education above secondary education had positive attitudes towards albinism and PWA while $50 \%$ of those with education level above secondary education, $31.25 \%$ of those with primary education and few $(9.57 \%)$ of those with no formal education could not express their attitudes. Attitudes towards albinism and PWA were highly associated with education level of respondents in which those with no formal education had negative attitudes which decreased with the increase in education level (i.e. 100\% with no education, $88.7 \%$ with primary school education and $0.0 \%$ among those with higher education levels). The association of attitudes with education levels was statistically significant $(p<0.001)$.

Ignorance makes people to discriminate against each other, thus awareness and education are the keys to overcoming discrimination (BBC, 2006). Ohlander et al. (2005) insist that the relationship of education and attitudes is not a spurious one but there is obvious liberalizing effect of education on attitudes. This 
Table 3. Factors associated with attitudes towards Albinism and PWA.

\begin{tabular}{|c|c|c|c|c|}
\hline \multirow[t]{2}{*}{$\underline{\text { Variables }}$} & \multicolumn{3}{|c|}{$\frac{\text { Attitude towards albinism and }}{\text { people with albinism (\%) }}$} & \multirow[t]{2}{*}{$\frac{\underline{\text { Significance }}}{\underline{\underline{\text { levels }}}}$} \\
\hline & $\begin{array}{l}\text { Negative } \\
\text { Attitudes }\end{array}$ & Undecided & $\begin{array}{l}\text { Positive } \\
\text { attitudes }\end{array}$ & \\
\hline \multicolumn{5}{|l|}{ Type of respondent } \\
\hline Persons with albinism $(\mathrm{n}=36)$ & 72.20 & 13.90 & 13.90 & $\chi^{2}=2.198$ \\
\hline PWA relatives $(\mathrm{n}=80)$ & 62.50 & 26.30 & 11.20 & $p=0.699 \mathrm{~ns}$ \\
\hline Heads of family $(\mathrm{n}=40)$ & 65.00 & 22.50 & 12.50 & \\
\hline \multicolumn{5}{|l|}{ Age categories } \\
\hline $0-15$ years $(n=7)$ & 85.71 & 14.29 & 0.00 & \\
\hline $16-30$ years $(n=26)$ & 76.92 & 15.38 & 7.69 & $\chi^{2}=10.526$ \\
\hline $31-45$ years $(n=64)$ & 85.94 & 10.94 & 3.13 & $p=0.230 \mathrm{~ns}$ \\
\hline $46-60$ years $(n=41)$ & 78.05 & 4.88 & 17.07 & \\
\hline $61-75$ years $(n=18)$ & 66.67 & 16.67 & 16.67 & \\
\hline \multicolumn{5}{|l|}{$\underline{\operatorname{Sex}}$} \\
\hline Males $(n=92)$ & 76.09 & 10.87 & 13.04 & $\chi^{2}=4.595$ \\
\hline Females $(n=64)$ & 85.94 & 10.94 & 3.13 & $p=0.101 \mathrm{~ns}$ \\
\hline \multicolumn{5}{|l|}{ Education levels } \\
\hline Not gone to school $(\mathrm{n}=23)$ & 100.00 & 0.00 & 0.00 & \\
\hline Primary educ. Level $(n=115)$ & 88.70 & 9.57 & 1.74 & $x^{2}=1.044$ \\
\hline Secondary educ. Level $(n=16)$ & 0.00 & 31.25 & 68.75 & $p<0.001^{\star * *}$ \\
\hline Beyond sec. educ. Level $(\mathrm{n}=2)$ & 0.00 & 50.00 & 50.00 & \\
\hline \multicolumn{5}{|l|}{ Occupation } \\
\hline Peasant $(\mathrm{n}=130)$ & 87.69 & 8.46 & 3.85 & \\
\hline Government employee $(\mathrm{n}=19)$ & 31.58 & 26.32 & 42.11 & $\chi^{2}=43.600$ \\
\hline Traditional leader $(\mathrm{n}=4)$ & 100.00 & 0.00 & 0.00 & $p<0.001^{* * *}$ \\
\hline Religious leader $(\mathrm{n}=3)$ & 33.33 & 33.33 & 33.33 & \\
\hline
\end{tabular}

${ }^{* *}=$ significant at $p \leq 0.001 ; \mathrm{ns}=$ not significant at $p \leq 0.001 ; \chi^{2}=$ Chi-square.

suggests that negative attitude of the community is to change as people know more about albinism and PWA. Then widespread dissemination of accurate information about the genetics and health management of albinism is relevant measure to counter the many myths and misconceptions surrounding albinism and PWA (Lund, 2001).

Murders of albinos are, to a large extent, fuelled by spiritual, cultural and or religious beliefs as well as lack of understanding of the causes of albinism. Stigmatization and discrimination obvious affect lives of PWA and their families. Behavior like the killing of PWA and old women regarded as witches can be traced from the way socialization processes take place and might have been in favor of many cultural backgrounds which lead to illusory correlations (Tanner, 
2010). In this case Sukuma beliefs that magic "medicines" containing human body parts are correlated to relief of serious personal misfortunes will be possible to be declared scientifically impossible and socially irrelevant.

\subsubsection{Association between Respondents' Occupation and Attitudes towards Albinism}

The findings show that, while all (100\%) traditional leaders had negative attitudes towards albinism, $87.69 \%$ of peasants had negative attitudes too (Table 3 ). Only Government employees had a slightly higher proportion of respondents (42.11\%) who had positive attitudes towards albinism and PWA. Traditional leaders were equally divided in which $33.33 \%$ of them had negative attitude and the same had positive attitudes and $33.33 \%$ remained undecided. This shows a high proportion of traditional leaders and peasants having negative attitudes while Government staff having positive attitudes towards albinism and PWA. Such findings are very painful experience for PWA who actually would need physical expressions of love, care, interaction and acceptance from the whole community. Lund \& Gaigher (2002) explain the negative attitudes towards PWA as unhappy consequence for PWA being labeled as socially unacceptable and that people's stigma can come to dominate the perceptions that others have.

Negative attitudes among traditional leaders and peasant confirm the fact that negative attitudes toward albinism reflect a general lack of information and a degree of negativism in a respective community (Estrada-Hernández \& Harper, 2007). Though traditional healers are mostly blamed to be behind the killings, traditional leaders are also said to be behind the killing of children with albinism secretly as far as the killings are related to culture and traditions which traditional leaders are custodians of. Sukuma traditions demanded killing of babies with albinism as soon as they were born and baby's remains were used for witchcraft rituals (UTSS, 2012). Traditional leaders were keen enough to see that people adhere to traditional norms so as to keep the community safe from angry gods. During data collection, a person with albinism was thankful for her late mother for refusing to kill her once she was born in their rural village in 1977. The mother was several times instructed by her neighbors and traditional leaders to fulfill the requirement of Sukuma culture by burying her child alive or throwing her in a river since she was an unwanted child in the community. Being a devoted Christian she refused to commit the offence. Such practices are said to be practiced in rural areas of Tanzania as the Daily News (2011) wrote:

"In rural Tanzania, in the past, newborn albinos were sometimes killed right after birth. Although the practice is less common in most parts of Africa today, it is still practised in some rural areas, according to the Tanzanian Albino Society (TAS)."

Though those who were government employees showed some degree of positive attitudes, they are not capacitated enough to change their attitudes. With expectation that government employee might be knowledgeable enough and thus have positive attitudes, The Daily Mail (2011) reports that: 
"Teachers, nurses and our government leaders don't know enough about albinism. We need education campaigns ..."

According to Dave-Odigie (2010), greater accessibility to education in the nation's rural areas could play a crucial role of moving people away from various forms of irrational beliefs that help drive the ritual practice of killing albinos for their body parts. However, it will take more than awareness and education to stop superstitious discrimination and stigma because such beliefs are deep-seated in African traditional culture and religion and may be held to some degree even by more highly educated individuals (Anderson, 2004).

\section{Conclusions and Recommendations}

\subsection{Conclusions}

Awareness (knowledge) on albinism among family members is moderate. Categorically, awareness is poor among those with lower or with no formal education while awareness increases with increase in age categories and formal education level. Males seem to be slightly more aware than females. The study shows that, awareness is highly associated with religious affiliation and ethnic groups of respondents. Attitude towards albinism and PWA is poor, the problem is highly associated with high level of illiteracy. Relationships between education, attitudes and awareness confirm the liberalizing effect of education on attitudes and general awareness on community related issues.

\subsection{Recommendations}

Since illiteracy is the main force behind the beliefs and attitudes towards albinism and PWA. A policy for a long time solution should be formulated to insist on awareness of pupils on albinism from lower schools levels. This will comparatively increase understanding on albinism condition which is lacking among people with low level of education. Awareness on albinism should be accompanied with socialization of children with positive attitudes towards PWA. This will ensure having a nation with positive attitudes towards PWA as well as to other people with other forms of disabilities. This will widen the understanding of albinism and will help young people not to hold on cultural beliefs on the cause of the condition.

\section{Conflicts of Interest}

The authors declare no conflicts of interest regarding the publication of this paper.

\section{References}

Aljazeera (2009). Life of Fear for Tanzania's Albinos: A String of Murders of White-Skinned Residents Has Shocked the African Country.

http://www.aljazeera.com/programmes/general/2008/08/20088171455171120.html

Allen, K. (2010). Oppression through Omission: The Human Rights Case of Persons with 
Albinism in Uganda.

http://www.underthesamesun.com/sites/default/files/Kelly\%20Allen\%27s\%20research \%20on\%20PWA\%20in\%20Uganda.pdf

Anderson, D. W. (2004). Human Rights and Persons with Disabilities in Developing Nations of Africa. In The Fourth Annual Lilly Fellows Program National Research Conference Christianity and Human Rights (21 p.).

BBC (2006). What Do You Know about Albinism? http://news.bbc.co.uk/2/hi/africa/4997644.stm

BBC (2008). Tanzania in Witchdoctor Crackdown. http://news.bbc.co.uk/2/hi/africa/7327989.stm

Braathen, S. H. (2005). Albinism in Malawi. A Qualitative Study on Attitudes and Beliefs (66 p.). Thesis for Award of Master of Philosophy Degree in International Community Health at University of Oslo.

Clarke, H. (2006). Preventing Social Exclusion of Disabled Children and Their Families. Literature Review Paper Produced for the National Evaluation of the Children's Fund. http://www.dfespublications.gov.uk

Daily Mail (2011). Albino Child Who Disappeared on Way Home from School Was Kidnapped by Witch Doctors for Tribal Sacrifice.

http://www.dailymail.co.uk/news/article-2010889/Albino-child-disappeared-way-hom e-school-was-kidnapped-witch-doctors-tribalsacrifice.html\#ixzz2LLXrwUd5

Daily News (2011). Documentary on Albinism Impresses Local Communities. http://dailynews.co.tz/feature/?n=18453

Dave-Odigie, C. P. (2010). Albino Killings in Tanzania: Implications for Security. Peace Studies Journal, 3, 68-75.

Estrada-Hernández, N., \& Harper, D. C. (2007). Research on Psychological and Personal Aspects of Albinism: A Critical Review. Rehabilitation Psychology, 52, 263-271. https://doi.org/10.1037/0090-5550.52.3.263

Ford, J. D. (2014). Attitudes toward Persons with Albinism among a Sample of Barbadian and Trinidadian Nationals. Caribbean Educational Research Journal, 2, 32-49.

Good and Bad Culture (2012). African Culture at a Glance. http://www.good-and-bad-culture.com

Harris, C. (2011). Attitudes, Behavior, and Social Practice. The Journal of Sociology and Social Welfare, 38, 31-54.

Hogan, S. (2012). Fear of White. http://www.ourworldtoday.com.au/news/article/fear-of-white

IPPMEDIA (2012). Revisiting Adam's Tragic Story: How a Father Sold His Albino. http://www.ippmedia.com/frontend/index.php?l=49091

Jozen, A. (2012). Signs of the End: Converting Albinos into Capital. http://www.ippmedia.com

Kiprono, S. K., Joseph, L. N., Naafs, B., \& Chaula, B. M. (2012). Quality of Life and People with Albinism in Tanzania: More than Only a Loss of Pigment. Scientific Reports, 1, $2-83$.

Lipenga, K., \& Ngwira, E. (2018). "Black on the Inside": Albino Subjectivity in the African Novel. Disability and the Global South, 5, 1472-1487.

Lubus, J. (2010). The Practice of Witchcraft in Tanzania in Relation to Killings of Albino and Old Women. http://witchcraftintanzania.wordpress.com

Lund, P. M. (2001). Health and Education of Children with Albinism in Zimbabwe. 
Health Education Research. Theory and Practice, 16, 1-7. https://doi.org/10.1093/her/16.1.1

Lund, P. M., \& Gaigher, R. (2002). A Health Intervention Programme for Children with Albinism at a Special School in South Africa. Health Education Research. Theory and Practice, 17, 365-372. https://doi.org/10.1093/her/17.3.365

McLin-Bronson, H. R., Paige, S. D., Berrett, K. S., \& Wilson, C. D. (2009). Women, Children, Families and Social Change in South Africa. http://www.jsums.edu/cll/new\%20website\%202008.2/pdf/Women\%20Children\%20Fa milies\%20and\%20Social\%20Change\%20in\%20South\%20Africa.pdf

Moe, C. (2011). Persecution of Albinism in Tanzania. http://prospectjournal.org/persection-of-albinism-in-tanzania

Mswela, M. M. (2016). A Selection of Legal Issues Relating to Persons Living with Albinism (372 p.). Thesis Submitted in Accordance with the Requirements for the Degree of Doctor of Laws at the University of South Africa, 28th February, 2016.

Mtholyoke (2009). Killings of Albinos in Tanzania: Causes of the Killings. http://www.Mtholyoke.edu/ marik22b/classweb/worldpolitics/page\%202\%20kiling\%2 0of\%20albino\%20tab2.html

Nemec, J. (1974). Witchcraft and Medicine. US Department of Health, Education and Welfare. http://www.nlm.nih.gov/hmd/pdf/witchcraft.pdf

Nzagi, I. (2009). Securing the Rights of People with Albinism in Tanzania Mainland: The Fight against Social Exclusion (59 p.). Dissertation for Award of Degree of Masters of Arts in Development Studies Specialization in Human Rights, Development and Social Justice.

Ohlander, J., Batalova, J., \& Treas, J. (2005). Explaining Educational Influences on Attitudes toward Homosexual Relations. Social Science Research, 34, 781-799.

PHPAFRICA (2012). Community Engagement Project to Address Problems Faced by Albinos.

http://www.phpafrica.org/projects/community-engagement/community-engagement-p roject-address-problems-faced-albinos

Rohwerder, B. (2018). Disability Stigma in Developing Countries. https://assets.publishing.service.gov.uk/media/5b18fe3240f0b634aec30791/Disability st igma in developing countries.pdf

Rwebangira, M. K. (1996). The Legal Status of Women and Poverty in Tanzania (29 p.). Research Report No. 100, Motala: MotalaGrafiska.

Samdani, A. J., \& Khoso, B. K. (2009). A Unique Albino Village of Bhatti Tribe in Rural Sindh, Pakistan, with Oculocutaneous Albinism Manifestations: An Epidemiological Study. Iranian Journal of Dermatology, 12, 42-46.

Stensson, E. (2008). The Social Stratification of Albinos in Tanzania: A Case Study from Babati (32 p.). Thesis for Award of Bachelor Degree at Södertörn University College, Stockholm: Institution of School of Life Sciences 15 ECTS, Development and International Cooperation.

Tanner, R. (2010). Ideology and the Killing of Albinos in Tanzania: A Study in Cultural Relativities. Anthropologist, 12, 229-236. https://doi.org/10.1080/09720073.2010.11891161

Taylor, J., Jones, C. B., \& Lund, P. (2019). Witchcraft-Related Abuse and Murder of Children with Albinism in Sub-Saharan Africa: A Conceptual Review. Child Abuse Review, 28, 13-26. https://doi.org/10.1002/car.2549

The Citizen (2011). Welcome to Juju Nation! Tanzania. 
http://eldritchmisc.wordpress.com/2011/07/23/welcome-to-juju-nation-tanzania

Thuku (2011). Myths, Discrimination, and the Call for Special Rights for Persons with Albinism in Sub-Saharan Africa.

http://www.underthesamesun.com/sites/default/files/MYTHS.Final .pdf

UN (2016). Enjoyment of Human Rights by People with Albinism: Note by the General Secretary. https://undocs.org/pdf?symbol=en/A/71/255

UN News Centre (2008). UNICEF Calls for Crackdown on Albino Murders in Tanzania. http://www.un.org/apps/news/story.asp?NewsID=29409\&Cr=albinoo\&Cr1

UNICEF (2011). Knowledge, Attitude and Practices: Study on Children with Albinism in Nigeria.

https://albinofoundation.org/wp-content/uploads/2017/03/UNICEF-Report-on-Childr en-with-albinism-in-Nigeria.pdf

UTSS under the Same Sun (2012). Children with Albinism in Africa: Murder Mutilation and Violence. A Report on Tanzania with Parallel References to Other Parts of Sub-Saharan Africa.

http://www.underthesamesun.com/sites/default/files/UTSS\%20report\%20to\%20UN\%2 0-\%20REPORT0.pdf

Wilkinson, B. (1998). Elimination of Prejudice against Albino Children in Africa. http://gbgm-umc.org/africa/zimbabwe/albino.html 